This item was submitted to Loughborough's Research Repository by the author.

Items in Figshare are protected by copyright, with all rights reserved, unless otherwise indicated.

\title{
Disrupted becomings: The role of smartphones in Syrian refugees' physical and existential journeys
}

PLEASE CITE THE PUBLISHED VERSION

https://doi.org/10.1016/j.geoforum.2019.05.012

\section{PUBLISHER}

(C) Elsevier BV

\section{VERSION}

AM (Accepted Manuscript)

\section{PUBLISHER STATEMENT}

This paper was accepted for publication in the journal Geoforum and the definitive published version is available at https://doi.org/10.1016/j.geoforum.2019.05.012

\section{LICENCE}

CC BY-NC-ND 4.0

\section{REPOSITORY RECORD}

Gough, Hannah A., and Katherine Gough. 2019. "Disrupted Becomings: The Role of Smartphones in Syrian Refugees' Physical and Existential Journeys”. Loughborough University. https://hdl.handle.net/2134/37923. 


\title{
Disrupted becomings: The role of smartphones in Syrian refugees' physical and existential journeys
}

\author{
Hannah, A. Gough and Katherine V. Gough
}

\begin{abstract}
This paper explores the role of smartphones in facilitating the journeys of predominantly young, male Syrians following the onset of the civil war. Drawing on in-depth interviews conducted with Syrian refugees who have reached Denmark but are at different stages of the asylum process, it traces the multiple disruptions they have experienced and delves into the ways in which they navigate in their search for a better life. Their smartphones are shown to be vital tools in a myriad of ways at all stages of their physical and existential journeys starting from their lives in Syria and then Turkey, the boat crossing to Greece, overland through Europe, seeking asylum and settling into Denmark. The concept of 'chronic disruption' is developed to capture the ways in which refugees are constantly facing new hurdles in their lives, which smartphones play a key role both physically and existentially in their attempts to overcome. This paper makes an original contribution to migration studies by bringing together an analysis of the role smartphones play as part of migration infrastructure, both in facilitating access to the migration industry and shaping migrants' journeys, aspects which are rarely brought together in one study.
\end{abstract}

\section{Introduction}

During the 'Arab Spring' of 2011, Syrians took to the streets to protest against Bashar alAssad's government (Erlich 2014; Yazgan et al. 2015). Gradually the confrontations between protestors and the Syrian army became militarized turning into a "war between uncoordinated groups of anti-regime fighters on one side and the Syrian army, secret services and regimeloyal militias on the other' (Seeberg 2015: 23). The destabilisation of Syria has caused catastrophic destruction to the country on an 'unprecedented scale' (UNHCR 2016a: 38), with nearly half of the Syrian population having been forced to flee their homes to seek safety elsewhere, either within or outside the country. As conditions and prospects for Syrian refugees in neighbouring countries deteriorated, many decided to make the perilous journey to Europe in search of a better future (Yazgan et al. 2015; Gillespie et al. 2018), resulting in almost one million Syrians applying for asylum in Europe between April 2011 and October 2017 (UNHCR, 2018).

The exodus of refugees from Syria on a massive scale has coincided with a particular stage in mobile phone technology, as smartphones have become readily accessible to many individuals, making it a historically unique point in time. As Gillespie et al. (2016: 2) argue, 'For refugees seeking to reach Europe, the digital infrastructure is as important as the physical infrastructures of roads, railways, sea crossings and the borders controlling the free movement of people'. Whilst the refugee crisis has sparked interest in trying to understand the role mobile phones play in shaping the journeys of refugees and migrants (Frouws et al. 2016; Loh 2016; Zilstra and van Liempt 2017; Borkert et al. 2018), and on the use of mobile phones by Syrians within refugee camps in Jordan (Maitland et al. 2015; Fisher et al. 2016; Wall et al. 2017), to date no research has considered the role of smartphones in refugees' existential as well as physical journeys. 
This paper makes a novel contribution to the digital migration literature by analysing the role of smartphones in the journeys and lives of Syrian refugees ${ }^{1}$ living in Denmark, starting from their lives in Syria and then Turkey, the boat crossing to Greece, overland through Europe, seeking asylum and settling into Denmark, as they search for a meaningful life. Both the physical and existential journeys of eight informants, all of whom arrived in Denmark between August 2014 and August 2015, and are seeking or have recently obtained asylum, are explored. As is typical of Syrian refugees who made the hazardous overland journey to Europe during this time (cf. Alencar 2018; Borkert et al. 2018), they are well-educated, primarily young men who fled Syria after the crisis erupted and are experiencing disruptions to their existential quests to 'become someone'. As well as making an original empirical contribution, the paper develops the concept of 'chronic disruption', introduced to capture the ways in which refugees are constantly facing new hurdles in their lives. A core argument of the paper is that smartphones play a key role in refugees' attempts to navigate the chronic disruption they experience.

Following this introduction, the next section places the paper within the broader literature on migration and presents the analytical framework before the methodology adopted is subsequently outlined. The research findings are then divided into five sections corresponding to the various stages of our informants' journeys: life in Syria and Turkey, the boat crossing, overland through Europe, seeking asylum, and gaining residency. Throughout, the paper places particular focus on the role of smartphones in facilitating the Syrian refugees' physical and existential journeys.

\section{Migration, smartphones and social becoming}

The so called 'mass migration' to Europe in recent years has been widely discussed in the media and has become the subject of extensive research (see, for example, key texts by Andersson 2014 and Vradis et al. 2019). From a migration industry perspective, migration facilitation, control and the 'rescue industry' have been shown to form a complex web of relations, which migrants have to navigate (Schapendonk 2017; Cranston et al. 2018). The term 'migration infrastructure' has also emerged to highlight the 'systematically interlinked networks of actors, technologies and institutions that condition and facilitate migrant mobility' (Robertson 2017: 14, drawing on Xiang and Lindquist 2014). In a recent themed issue of this journal, however, Schapendonk et al. (2018: 3) claim that 'so far little attention has been paid to the shifting contexts migrants pass through', resulting in a call for a 'trajectory approach' to migration studies, which follows migrants' journeys through places rather than investigating them in places (cf. Zijlstra and van Liempt 2017). This paper makes an original contribution to migration studies by bringing together an analysis of the role smartphones play as part of migration infrastructure, both in facilitating access to the migration industry and shaping migrants' journeys, aspects which are rarely brought together in one study.

Advancements in digital technology enable people with smartphones to perform many activities on the move, changing the scope of access to, availability, and use of information by migrants. WiFi coverage has expanded at an exponential rate, transforming the ability to

\footnotetext{
${ }^{1}$ In this paper we use the term 'refugee' rather than 'migrant' because the Syrians interviewed were forced to flee a country in a state of war and fulfil the criteria for refugee under the UNHCR (2010: 3) protocol.
} 
access information with the aid of a smartphone (ITU 2016). New technologies and platforms have now become so ingrained that they are taken for granted as part of ordinary life (Miller et al. 2016), and losing them can cause social dislocation (Haddon 2004; Gillespie et al. 2018). Smartphones have become important vehicles for social media, acting as an enabling factor for online platforms such as Facebook, Whatsapp, Viber and Skype. The increasing affordability of smartphones in recent years has resulted in the rapid growth of smartphone possession (Miller et al. 2016) ${ }^{2}$. It has been argued that transnational migrants are often at the forefront of technology adoption as they find creative ways to appropriate ICTs to their advantage (Karim 2003; Panagakos and Horst 2006).

The 'refugee crisis' has sparked interest among academics and humanitarians trying to understand the role mobile phones play in shaping the journeys of refugees and migrants, though until recently, this research focussed on non-data phones (Frouws et al. 2016; Loh 2016). In the context of the Syrian crisis, studies have examined the use of mobile phones within refugee camps in Jordan, showing how their phones were by far the most popular medium for refugees to access the internet (Maitland et al. 2015; Wall et al. 2015). Fisher et al. (2016) found that the vast majority (88\%) of Syrian youth in the camps own mobiles and play an important role in assisting their friends and families through ICT wayfaring, especially using WhatsApp and Google.

For refugees who make the journey to Europe, recent studies have revealed how many would not have managed to navigate to their destinations without the use of their smartphones (Kaufmann 2016, 2018a; Zijlstra and van Liempt, 2017). Latonero and Kift (2018: 1) claim that 'in making their way to safe spaces, refugees rely not only on a physical but increasingly also a digital infrastructure of movement', consisting of social media, mobile apps, online maps, instant messaging, translation websites, wire money transfers, cell phone charging stations, and WiFi hotspots. Smartphones have thus been shown to be essential for refugee 'mobility, locatability, and safety' (Gillespie et al. 2018: 7) and are widely used; 95 percent of Syrian and Iraqi refugees who entered Europe in 2015 were found to use a smartphone during their journey to Europe and 'demonstrated an advanced degree of digital connectivity and literacy' (Borkert et al. 2018: 8). Dekker et al. (2018) have coined the term 'smart refugees' referring not only to their use of 'smart'phones but also their ability to develop 'smart' strategies of migration. At the same time, however, the digital traces that migrants leave make them vulnerable to surveillance and potentially intimidation by extremist groups (Gillespie et al. 2016, 2018; Latonero and Kift 2018).

Having arrived at their destination, mobile phones have been shown to be vital tools in solving everyday problems of survival for refugees and migrants and in attempts to integrate into the host society (Wilding 2009; Gifford and Wilding 2013; Coddington and Mountz 2014; O’Mara and Harris 2016; Leurs 2017). A relatively early study by Harney (2013: 548) showed how for asylum seekers, refugees and irregular migrants in Italy, their 'mobile was used as a tool to solve the everyday problems of survival'. Illustrating how times have changed, however, in order to use the internet these migrants had to frequent internet cafes. As recent studies have shown, ownership of smartphones enables refugees easy internet access regardless of whether they are settling in the Netherlands (Alencar 2018), Austria

\footnotetext{
${ }^{2}$ Whilst data on smartphone ownership in Syria is unavailable, CIA World Factbook (2014) estimated there were 86 mobile phone subscriptions per 100 inhabitants whilst the World Bank estimated there was 64 mobile phone subscriptions per 100 inhabitants in 2014.
} 
(Kaufmann 2018a) or France (Gillespie et al. 2018). Moreover, with interest in forced migration and media use steadily growing, transnational migration studies have revealed the importance of smartphones for maintaining links with friends and family in their country of origin and creating new connections in their current locations (Wilding 2006, Witteborn 2015, Borkert et al. 2018).

As Lim et al. (2016: 2148) claim, the 'role of ICTs in the shaping of migrant experience has inspired a rich and extensive body of research' from a range of disciplines including communication and media scholars, geographers, sociologists and anthropologists. The emerging subfield which explores the relation between migration and digital migration technologies is typically referred to as 'digital migration studies'. Despite a recent flurry of studies on digital migration, Leurs and Smets (2018: 8) claim that 'there is a relative lack of systematic academic research on the role of ICTs on the lives of forced migrants in Europe or wanting to move to Europe.' Moreover, in studies of migrants' use of digital media, 'refugee voices and experienced are lacking' (Gillespie et al. 2018:1). These are gaps that this paper contributes to filling.

Whilst drawing on and feeding into the digital migration literature, in order to explore the role of smartphones in refugees' existential as well as physical journeys, this paper is also framed by existential anthropological research, in particular the work of Ghassan Hage (2005), Hans Lucht (2012) and Henrik Vigh (2006, 2009a, 2009b). Ghassan Hage (2005) illustrates how 'existential movement' is central to understanding physical mobility, claiming that "migrants and would-be migrants, like everyone else in the world, like to feel that "they are going places'... it is only when they are 'going nowhere' or 'too slowly' in such familiar environments that they start thinking of physical mobility" (Hage 2005: 470). He found that the key issue for well-educated Lebanese was not being employed, rather it was the sense of going somewhere in life (existential mobility), which was just as important as physical mobility.

In a similar vein, in his study of the life-worlds of illegal Ghanaian immigrants in Italy, Hans Lucht (2012: 115) introduces the notion of 'existential reciprocity', which he defines as: 'the human need to have a relationship of exchange between individual and social needs and the environments capable of sustaining them, thereby drawing external reality into one's own sphere of influence and the centrality of this form of connectedness to understanding the decisions taken in high-risk emigration'. Lucht's (2012) notion of existential reciprocity informs our analysis of how Syrian refugees try to find a balance between where they want to go and where they are being taken by the world, thus helping to explain how they reinvent their worlds, partly through the use of their smartphones, in order to obtain a sense of control over their lives.

Henrik Vigh (2006, 2009a, 2009b) has made an important contribution to understandings of social becoming through his analytical optic 'social navigation', which he defines as being able to 'simultaneously keep oneself free of immediate social dangers and direct one's life through an uncertain social environment, towards better possible futures and improved life chances' (Vigh 2009a: 97). Whilst developed in relation to socially and politically marginalized young men in Guinea-Bissau, social navigation is a particularly apt concept to draw on here as the Syrian refugees' movements are constantly having to be adjusted to the changing environments they find themselves in, which affects their positions and trajectories (Vigh 2009b). Vigh (2008) also introduces the concept of 'chronic crisis', arguing that that for many people around the world, crisis is endemic rather than episodic due to situations of 
long-standing fragmentation and instability. Examining the social and experiential consequences of chronic crisis can provide insight into how such crises result in 'individual or existential crisis' (Vigh 2008: 15).

Whilst inspired by Vigh's concept of 'chronic crisis', we introduce the concept of 'chronic disruption', which we claim better depicts our informants' experiences. As the medical anthropologist Gay Becker (1998: 4) claims, people experience inner disruption 'when expectations about the course of life are not met ... such disruptions represent loss of the future.' As we show in this paper, our informants have had to cope with 'chronic disruption' as they have been experiencing continuous interruptions to their lives since the start of the Syrian crisis. Bringing together the concepts of social navigation, social becoming, existential mobility, and chronic disruption, frames our understanding of our informants' journeys to Denmark and their use of smartphones in their search for a meaningful life. The paper thus extends the emerging scholarly research focus on digital migration studies by bringing in the voices of Syrian refugees and highlighting not only the technological role of mobile phones but also their important existential role, as part of migration infrastructure, in shaping migrants' journeys and enabling access to the migration industry.

\section{Researching Syrian refugees' journeys}

Gaining access to Syrian refugees to interview in Denmark is challenging. Those who act as gatekeepers, for example in asylum centres, understandably tend to deny access to refugees due to the multitude of applications for interviews, and finding informants who are willing to speak about their often traumatic experiences is difficult. After attempts to gain access to asylum centres were unsuccessful, different avenues were pursued. A refugee community centre in central Copenhagen, Trampoline House, agreed to allow access to interview their members on condition of becoming a volunteer for six months. Volunteering in the centre not only provided access to potential informants but also an insight into the transitory and fragile nature of everyday life that refugees experience. Another avenue used to recruit informants was via a Syrian refugee already known to us, who not only agreed to be interviewed but also acted as a gatekeeper introducing us to other refugees. By using the snowballing approach from two different starting points, we managed to interview a total of eight Syrian refugees living in and around Copenhagen over a period of three months - March to May 2016. The interviews typically lasted around three hours.

Whilst time and resources did not allow us to adopt a true 'trajectory approach' in which we followed the refugees as they travelled (Schapendonk et al. 2018), in order to try to understand the shifting contexts they pass through, the in-depth interviews were structured so that the informants were first asked about their lives in Syria before and after the crisis started, before turning to discuss their journey to Denmark, their experiences since arriving in Denmark, and ending with their hopes and aspirations for the future. It was made clear from the start that our primary focus of interest was in our informants' use of their smartphones during all stages of their journeys. Apart from occasionally asking questions specifically about their use of smartphones, if our informants had not already specified this, the interviews proceeded without undue interference giving them the chance to focus on the aspects they considered important and felt comfortable talking about. For ethical reasons, we wanted to give our informants the power to decide what they wanted to disclose and emphasized that they did not have to go into detail regarding any painful experiences, which could be detrimental to their well-being. Nevertheless, the stories they told were sometimes distressing, both for them to recall and for us to listen to, as they involved recounting traumatic events, which required sensitivity and empathy as interviewers (Becker et al. 2000). 
On such occasions, we always gave our informants the option to halt the interview. Ensuring our informants' privacy and security was a key ethical concern and they were guaranteed anonymity and confidentiality.

As all the informants were middle-class, well-educated Syrians who spoke a good level of English, a translator was not required. Six out of the eight informants were Syrian men aged between 23 and 29, which is typical of the profile of Syrian refugees (cf. Alencar 2018; Borkert et al. 2018); the other two were a slightly older married couple (see Table 1). They were all given the option of being interviewed either individually or in pairs; Masood and Sada, Mubarak and Nasir, and Muhammad and Ali chose to be interviewed in pairs, whereas Sada, Abdul and Zamir preferred to be interviewed alone. Whilst recognising that our informants are only a fraction of the Syrian refugees who have reached Denmark, the interviews were very rich and we believe facilitate in-depth insights into their experiences. Other recent studies of migrants/refugees have similar sample sizes: Shapendonk (2017) had seven male respondents, Zijlstra and van Liempt's (2017) study was based on ten male and one female migrant, Kaufmann (2018a) and Hiuzinga and van Hoven (2018) researched ten primarily male Syrian refugees in Austria and the Netherlands respectively, whilst Pace (2018) interviewed nine young Syrian refugees in Denmark.

\section{INSERT TABLE 1 HERE}

The interviews were recorded on an iPhone, after obtaining informed consent, as this was the most convenient and least intrusive manner. The informants' own smartphones were also always on hand, which they produced many times to illustrate various points they were making, thus providing a visual lens into their life-worlds (see also Gillespie et al. 2018). The smartphone, therefore, was not only a focus of the research but was also used as a tool during the interview process, which greatly enhanced the discussions. As Kaufmann (2018b: 237) argues, 'locational and visual data produced by the smartphone ... open up new ways to talk with participants about their practices.' The interviews were subsequently transcribed ad verbatim and analysed using manual coding. An iterative and inductive approach was adopted to the research whereby an understanding was built up through on-going analysis and interpretation of the interviews, thus allowing for movement back and forth between theory and analysis, data and interpretation (O'Reilly 2009).

\section{Life in Syria and Turkey}

Smartphones were integrated into the everyday life of many Syrians prior to the onset of the war. Our informants recalled their smartphones at this time as being useful rather than a necessity, their main role being to facilitate social interaction via calling or WhatsApp (Miller et al. 2016). Alencar (2018) similarly found Syrian refugees used social media much less in their homeland prior to arriving in the Netherlands. As Mubarak explained:

Actually in Syria we don't need this much internet or the mobile because you know you are living with your family and your friends. You don't need all these kinds of programmes [apps] and if you want to go from work to another place you know the streets - you know how to move. It is easy ... people were not thinking too much about the internet so maybe they use the internet only for chatting on WhatsApp but that's it.

As the war in Syria progressed, the socio-economic and security environment became progressively worse (Yazgan et al. 2015). Instability and unpredictability became part of Syrians' everyday life as they entered into a terrain where they felt they had very little influence over their futures (Vigh 2008). Our informants tried to attune themselves to this 
difficult environment, tracking the constantly changing situation on their phones using group chats on WhatsApp and adjusting their decisions regarding whether to stay or leave as the crisis intensified. There were two acute triggers which made many young men decide to leave Syria: the disruption of their studies and the introduction of military conscription. Together these caused an existential crisis (Lucht 2012) and instigated their physical and existential journeys to Europe. As Nasir explained, it was only when he felt he was 'going nowhere' that he decided to start his journey, which was also the case for Hage's (2005) Lebanese informants.

While reaching Turkey initially provided our informants with the hope of finding employment and establishing a meaningful life, they could only work informally without any rights protection (Berti 2015), since it was not until January 2016 that Turkey introduced a law offering work permits to Syrian refugees. As is the norm, previous policy had barred refugees from entering the labour market (International Labour Organisation 2016). Our informants recalled the difficulties they faced as they tried to navigate in a country undergoing rapid change and declining economic prospects, while hosting a growing number of refugees. As the often exploitative informal work opportunities diminished or were never fulfilled, our informants experienced an existential crisis realizing that they could not achieve a meaningful life in Turkey, culminating in them feeling they had no choice but to make the journey to Europe. As Muhammad explained,

There is no future [in Turkey]. You cannot do anything. You do not have permission to do whatever you want or to make yourself a job or to complete your studies. It is so very hard. So we talk about coming here [Denmark] to find a way to complete our life.

Their smartphones became an essential tool while living in Turkey as they began to explore which country to move to and consulted personal contacts and the online refugee community regarding the best route to travel (Zijlstra and van Liempt 2017, Dekker et al. 2018).

\section{The boat crossing}

The boat crossing to Europe was the most feared and dangerous part of the journey, as Lucht (2012) also found for Guan migrants. While most of our informants did not wish to talk in detail about this part of their journey due to its traumatic nature, Ali and Muhammad shared their experience of crossing by boat from Bodrum (Turkey) to Kos (Greece) in detail, hence this section draws primarily on their experiences. Using their smartphones to help explain their journey, the brothers showed photos of how they spent the day relaxing on the beach with friends prior to embarking on the perilous crossing late one evening. These photos gave the impression of young people on holiday, and Muhammad and Ali recounted how they had enjoyed their couple of days in Bodrum, sending pictures back to their parents of selfies taken on the beach. This was in stark contrast to the next image Ali showed, which was a video documenting a short section of their boat crossing.

The brothers recounted how Ali had to take over the helm at times when the person in charge, whom they referred to as 'the Iraqi', became tired and frightened. As Lucht (2012) also found, according to our informants, this person was a refugee who had been placed in charge of the boat crossing by the smugglers in Turkey. Ali described feeling very scared while at the helm as he felt responsible for the lives of all the adults and children in the boat, around 50 people in total, and was aware that if the Turkish coastguards caught them they would be returned to Turkey. Using the app Maps.Me on his smartphone, which provides offline maps, 
Ali helped direct the boat towards Greece. Once he was sure they were in Greek waters, everyone onboard took out their mobile phones, which had otherwise been stored away safely in order to keep them dry and to not draw attention to the boat with light from the screens (Dekker et al. 2018), and waved their lit-up screens and torches in the hope that the Greek coastguards would find them. Ali showed the video that he took of this moment of the refugees wearing life-vests sitting almost on top of each other in the dark waving their mobile phones high up in the air. This small but significant incident highlights the ingenuity and creative uses mobile phones can have in the hands of their users (Schaub 2012), and how they can become a key element of their survival strategies.

While it is our informants who undertook the physical journey, their families form part of a wider social network becoming actors in the existential journey along with them (Lucht 2012). On reaching the island of Kos, the first thing Ali and Muhammad did was to find the nearest WiFi to let their parents know they had landed safely; as Gillespie et al. (2018: 5) also found, 'informing loved ones of their safe arrival is central'. They emphasised that this was the most important communication throughout their journey that they made to their parents, whom they knew were extremely worried due to the media posting almost daily incidents of boats over-turning and people drowning in the Aegean Sea. Similarly, Horst and Taylor (2014) reported that migrants engaged in border crossings between Haiti and the Dominican Republic would always use their mobile phones to let family members know as soon as they had arrived safely at their intended destination.

Periods of the journey without WiFi access could be problematic (Dekker et al. 2018), not just for those migrating but also for their families elsewhere. As Zamir explained, 'If I have internet then ... I will contact them but sometimes it is two days where I don't have.' Such 'blackout' periods from WiFi became metaphorical blackouts for family members nervously left behind, causing considerable distress. WiFi zones are thus much more than just technical in nature, acting as zones of familiarity and intimacy in the midst of unknown territory and upheaval, providing existential lifelines through facilitating contact with family members. In order to try to avoid such blackouts, Ali installed an app, which he bought for about $\$ 10$ that allowed him to hack into WiFi without having a password. Although he had known about this app previously, he waited until he reached Greece as he had learnt from other refugees that it was cheaper there. This was just one of the tactics that allowed Ali to innovately use his smartphone to its full advantage throughout his journey (Panagakos and Horst 2006; Zijlstra and van Liempt 2017).

Ali documented their waiting period on Kos by taking photos and selfies showing himself and his siblings happily posing and smiling as they felt they were progressing not only on their physical but also their existential journeys. It became clear that this was part of a trend in Ali's photo taking as he took almost exclusively images of the positive aspects of their journey. An important element of this was sending such photos 'back home', showing the importance of upholding a positive image of oneself and not instilling worry in others. The photo documentation thus served to ground our informants by cementing images of their wellbeing in the moment to their families. In a couple of photos, however, Muhammad could be seen sitting in the background looking tired and tense, which he explained was due to his feelings of trepidation over the next stage of their journey and bearing the weight of responsibility for looking after his siblings.

\section{Overland through Europe}


The remainder of our informants' journeys from Athens to Denmark was overland, hence, did not entail the level of danger of the boat crossing but was still fraught with challenges, especially crossing borders (Vradis et al. 2019). Even managing to use their smartphones could be problematic. Mubarak recalled how on his journey from Greece to Denmark through Eastern Europe, he encountered problems trying to use his smartphone in different countries:

\begin{abstract}
After we went out from Greece it started to become difficult to use your phone because every country you have to buy a new sim-card... It is difficult because we don't have papers and don't have passports so I think we were out from the internet in Eastern Europe until we came to Denmark but every time we had a chance to use the internet like maybe at the hotels or something then we use it.
\end{abstract}

As Ali was the most technologically adept amongst his siblings, despite being the younger brother he was in charge of deciding which route to take and tracking their progress on his smartphone. Nevertheless, all three siblings discussed where to go and how, which frequently had to change as they navigated their way through the constantly evolving situation (Vigh 2009b). The siblings managed to cross into Macedonia by using a combination of following their planned route on the Maps.Me app and constantly checking the various WhatsApp/Viber/Facebook groups of the online refugee community, which continually updated whether a border was open or closed and offered advice on when and where it was best to attempt to cross. As Gillespie et al. (2016) claim, and our informants indicated, WhatsApp and Viber are especially popular as these apps are not subject to surveillance. Due to consulting the online community, Ali and Muhammad were aware that the biggest risk after the boat crossing was being caught crossing the Serbia/Hungary border. A smuggler dropped the siblings in the middle of the night at an isolated spot close to this border, from where they had to find their own way. They struggled, however, as their previously downloaded maps from Maps.Me lacked of detail due to attempts by the military to protect the border. Moreover, they were concerned that the light from the smartphone would attract the attention of the border police, so every time Ali got out his phone to check the map, the rest of the group would huddle over him to block the light. As he said, while laughing nervously, 'Everyone is scared so they were smashing me.' Although having a smartphone was invaluable at this point, it could have led to their detection.

Zamir, also travelling with his two younger siblings, took a similar route to Ali and Muhammad, making his way through Greece heading for Macedonia but after they were stopped by a border patrol they had to find an alternative route. Zamir explained how he was constantly checking on Facebook pressing, 'Update, update, update,' whilst he tried to figure out the best route to take. After successfully crossing into Macedonia, the brothers took a train close to the Serbian border from where they walked over the mountains into Serbia. Zamir described vividly:

No taxi, no buses, no nothing. We should walk. Walk, walk, walk. We are so tired and when we walk here there was water [gestures to over his ankles] and my shoes have a lot of water and it is so hard when your shoes have water.

After crossing into Serbia, Zamir used a WhatsApp group to find a smuggler who took them to a bus station, enabling them to catch a bus to Budapest. Aware that he had to be very careful in Hungary, Zamir used his phone to consult the online refugee community for information about which hotel to stay in, where to find a smuggler, and the cost of travelling from Budapest to Germany. He succeeded in finding a smuggler who would drive them to 
Germany for 1,200 Euros. Just as they were leaving Budapest, however, the car they were travelling in was pulled over by the Hungarian police. Here Zamir describes what happened next:
We follow him [police officer] to some area where there are no people there and then I put 100 Euro in my hand and then I give it to the police and I look at them. They say 'It is big problem' and then I take 200 Euro more and I give it to them then they said 'Go.' When they said 'Go!' I feel good but what should I do now? I should pay the smuggler 1,200 but I pay to the police 300 Euro so I just have 900 Euro left. So I call my father's friend and said what happened to me and he said don't worry give me the smuggler and so I give him the smuggler and he said give me your bank account and I can give you the money. When he sent it then the smuggler said no problem.

It is not uncommon for refugees to face corruption and extortion along their journeys (see also Schapendonk 2017), but when in a tight corner it was having access to a smartphone that enabled Zamir to resolve the situation. As Collyer (2007: 674) claims, 'Instant international money transfers provide many migrants with a lifeline to home, or relatives or friends elsewhere'.

Ali also consulted the online refugee community when trying to work out the best route out of Budapest. Taking advantage of free WiFi in Burger King, Ali asked a WhatsApp group, 'Are there any smugglers in Budapest, Hungary?' He received contact details for a smuggler, who responded by sending them via WhatsApp a location to meet in Budapest. Following negotiations, the siblings left Budapest crammed into the back of a white van without any windows or seats, along with around 30 other people. After six uncomfortable hours they successfully crossed the border into Germany. Ali showed a photo taken on the day they reached Germany in which Muhammad is smiling, the first photo in which he is doing so since those taken on the day they left Turkey. Muhammad explained this was because he thought his journey was now over, i.e. his physical journey had ended and he would have the opportunity to begin to navigate towards a more positive future (Vigh 2009b).

After spending several days in appalling conditions in a German asylum camp, however, the brothers decided they needed to keep on moving and try to reach Denmark - an example of how 'decisions on migration routes and methods are not defined from the outset and might change while in transit' (Zijlstra and van Liempt, 2017: 182; see also Collyer 2007). By pure chance, the driver of the taxi they hailed was Turkish and as they travelled through Germany Ali fell into conversation with him, helped by being able to converse in Turkish. Ali discovered that the taxi driver's wife, who was Iraqi, worked in a tourist office and after he called her she advised that the best route for the siblings to take to Denmark was the ferry from Puttgarden. As the brothers kept repeating 'Very good luck' was on their side now. On arriving in Puttgarden in the early hours of the morning one day in August 2015, the taxi driver assisted them in buying tickets and boarding the ferry. The three siblings then sailed smoothly into Danish waters. The brothers were almost giddy re-telling this part of their journey because they can still hardly believe their luck. Regardless of how well prepared and adept refugees are at using their smartphones in numerous innovative ways, both good and bad luck play a role in their journeys (cf. Schapendonk 2017).

Mubarak recalled one episode of extreme bad luck, which occurred while travelling by taxi with his friend during the middle of the night in some Eastern European mountains. As he explained: 
So someone had told him [smuggler] that a police patrol car was waiting and he suddenly stopped the car and said 'GO! MOVE! MOVE! MOVE!' So we opened the door but I had been sleeping and my phone was on my legs so when he said 'GO! POLICE! POLICE!' then I woke up and jumped out of the car but my phone fell inside his car. I lost everything.

From this point onwards, Mubarak was without a smartphone, which impacted greatly on his journey and ability to maintain contact with his family. His only option was to borrow other people's smartphones, which he could only do occasionally. He recalled connecting to the internet after three or four days of being without and seeing many frantic messages from his family. As Hage (2005) claims, refugees' families are also part of their existential journeys, which today smartphones play a key role in facilitating.

\section{Seeking asylum}

The length of the asylum procedure varies in Denmark because decisions are made on a caseby-case basis, resulting in the process being riddled with insecurity (Whyte 2011; Pace 2018). Hence, for some asylum seekers it only takes a couple of months to receive permission to stay, whilst for others it can take up to and even over one year. Despite Ali and Muhammad having arrived in Denmark in August 2015, they were still waiting for an answer to their asylum application one year later. After the huge sense of relief of arriving at their final destination safely came a feeling of anti-climax. Ali and Muhammad described the boredom and loneliness of being enclosed in a small, shared room in Sandholm Asylum Centre with no privacy and nothing to do. Similarly, Witteborn's (2015) research in Germany illustrates how forcing asylum seekers into small, often overcrowded accommodation impacts on their sense of being. The smartphone played an important role in filling the vacuum Ali and Muhammad had entered, enabling them to be existentially elsewhere:

Muhammad: We spent all day on our phones in Sandholm and at the beginning here [Roskilde Asylum Centre].

Ali: Yeah because you don't want to just be in the room sleeping and eating. It is no life at all.

Zamir also recalled arriving to register as an asylum seeker at Sandholm with high hopes of starting his new life soon, a feeling shared by his social network. As he explained:

We should tell everyone and my family and my friends that I am here and that I am safe. So that is really good and you know they are happy like me all of these people because they know that I am now safe and maybe I will now start a new life.

Despite this initial feeling of hope for the future, Zamir explained how, like Muhammad and Ali, he almost immediately experienced an anti-climax as the high levels of adrenaline from being in a state of fight or flight mode for the 20 days of his journey, abruptly came to an end. Not only was he struggling from his physical mobility being restricted, as he spent hours on end confined to a small space (cf. Borkert et al. 2018), he now felt like he had zero control regarding decisions on his life, in sharp contrast to his journey. 'When does my new life start to begin?' he kept asking those around him. Zamir used his smartphone to remain in frequent contact with his friends and family in order to temporarily escape from his day-to-day boredom and frustration. Similarly, Witteborn (2015) found that new technologies enabled asylum seekers in Germany to take back one area of control in their lives and provided an opportunity for them to enhance their sociality and build up networks. 
Mubarak and Nasir also had vivid memories of the initial registration period. A positive aspect was meeting each other early in this process and quickly becoming good friends. Although their applications were processed relatively quickly, it felt like a long time to them and they too tried to escape the boredom and monotonous daily routine by using their smartphones. As they recounted, during this period:

Nasir: You just sleep, eat and phone.

Mubarak: You feel so bored in the camp [Asylum Centre]. Of course we need mobile phone, we need internet, we need it all the time. You have nothing to do only sleep and speak on the mobile.

In accordance with international law, asylum seekers are unable to work or pursue higherlevel education, hence there is little to fill their days. Smartphones provide an existential lifeline to help fill the void they experience, aiding them to pass the time and ensure their lives have an element of familiarity and intimacy by sharing photos and experiences with close friends and family. The smartphone thus becomes the most important object in asylum seekers' lives because it allows for feelings of control and opportunity, enabling them to exercise a level of agency in a situation that they otherwise have very little control over; it becomes an existential lifeline by helping fill their everyday vacuum and create glimpses of possible futures (Vigh 2009b).

As the asylum seekers are moved from the initial registration asylum centre in Sandholm to a residency asylum centre, such as the one in Roskilde where Ali and Muhammad were interviewed, their waiting manifests in feelings of being isolated and detached from the wider Danish society - a sense heightened by their surroundings (Whyte 2011, Pace 2018). As Muhammad explained, he does not feel that he has truly experienced Denmark:

I do not really know Denmark yet. I do not have experience enough because it is only my journey but in Denmark I do not have experience because I do not go outside so much. I have not seen real life in Denmark.

Consequently, Muhammad did not feel he was able to share with other refugees online whether Denmark is a good or bad place to seek asylum as his 'new life' has yet to start. Being unable to be seek employment means the brothers' lives have stagnated as they are unable to move towards their goals and aspirations of being successful career-minded young men. As Whyte (2011) argues, the increasing restrictiveness of the Danish asylum process has resulted in uncertainty becoming an ingrained part of the asylum system. For asylum seekers in Denmark, 'the core uncertainty, that of the outcome of their cases, meant that few applicants dared speak with any confidence of their futures, which would be radically different depending on the authorities' decision' (Whyte 2011: 19). Moreover, as Bendixen (2018) illustrates, the chance of being granted asylum in Denmark has fluctuated in recent years: 'In 2015 it reached a record high of $85 \%$, in 2016 it dropped to $72 \%$, and in 2017 it ended at $36 \%$, with some months as low as $28 \%$.' Since their future is still overwhelmed by uncertainty, Ali and Muhammad do not feel like they are progressing along a positive social trajectory (Vigh 2006) and are unable to fulfil their desires of being successful young Syrian men; they are experiencing 'chronic disruption' in their search for a meaningful life. Like many others in their situation, they relied heavily on their smartphones as an aid in trying to socially navigate (Vigh 2009b) through this period of insecurity. 
Similar to Ali and Muhammad, Zamir and his brothers were moved from Sandholm to Roskilde Asylum Centre to await their residency verdict, which took eight months. After experiencing an initial existential impasse (Hage 2005), with the help of his well-connected family Zamir began to form relations outside of the isolating asylum centre, through which he met his Syrian/Danish girlfriend. By combining the resources of their respective families, Zamir was able to buy his youngest brother a smartphone for his birthday. Importantly, it was the latest Samsung Galaxy phone, illustrating the symbolic importance of smartphones. These actions are similar to Lucht's (2012: 88) finding for Ghanaian migrants in Italy that, 'the first thing many would do was to purchase an expensive mobile phone - not just any mobile phone, but often the most 'powerful' one they could find.' Alongside practical reasons for owning the latest mobile phone, as the case of Zamir illustrates and Lucht (2012: 88) claims, 'the mobile phone is also the quintessential symbol of having connections to the world'.

As they await the decisions on their asylum cases, or as they put it, 'Start my new life', the asylum seekers spend a considerable amount of time using their smartphones to maintain transnational social relations with their family and friends, whom they come to rely on as they wait out this period of uncertainty. Similarly, for young refugees in Germany (and as Alencar 2018 also reports for the Netherlands) the 'smartphone is central, as communication and contact with family and friends represent a top priority for young people' (Kutscher and Kreb 2018: 6). Ali and Muhammad described how they are in constant contact with friends and family, messaging over WhatsApp, Viber or Facebook. As Muhammad explained, however, the frequency of their contact with their parents is mainly dependent on the internet in Syria, which is highly unreliable:

They call us when they can. Every chance they have to reach to us. If there is good internet then they make a video call but the internet in Syria is too bad. Instead they voice-call either through Facebook messenger or Whatsapp.

The family members not only speak with each other whenever possible but also share images, whether it is the food they are eating or a selfie. The brothers burst into fits of laughter when they showed us one of the short video clips their father had sent with commentary on his daily life in Damascus. As Muhammad explained:

We do like it but he is just holding the camera and talking: 'This is a man. This is the shop where I brought my rice. This is...this is...' He is just filming and explaining.

It is the smartphone that enables the brothers to maintain these virtual intimacies (Wilding 2006). Being able to laugh and joke about their father's video skills highlights one of the ways in which long distance family relationships are maintained.

\section{Residency - now what?}

Mubarak, Nasir, Abdul, Masood and Sada had all obtained residency in Denmark around one year prior to being interviewed. They emphasized how their smartphones were aiding them settle into their new lives and maintain transnational social relations (Alencar 2018, Kaufman 2018; Kutscher and Kreb 2018). Their experiences since gaining residency are presented here in turn.

Mubarak and Nasir were living in shared accommodation on the outskirts of Vedbæk Kommune (20 km from the centre of Copenhagen) in a rather depilated grand old building. They had both imagined that their new lives would start after the vital conjuncture (JohnsonHanks 2002) of obtaining residency, however, over one year later they were despondent 
about both their accommodation and job situation. Mubarak had been recently forced into taking a paper delivery night shift, despite having an economics degree, while Nasir was working in a garage, which had nothing to do with his tourism degree but he saw at least as an opportunity to improve his Danish. Both young men, however, were experiencing social truncation (Vigh 2006) by not having employment that matched their skills, and disillusionment with their current situation had set in as their social position stagnated. Their search for meaningful lives continues to be disrupted, similar to the 'existential impasse' experienced by Guinean migrants in Lisbon (Vigh 2009a). The future of these young Syrian refugees has turned into negative imaginaries as they are once again stuck in a limbo period unable to move towards their desired state of adulthood. They are experiencing 'chronic disruption' to their lives.

Owning a smartphone, however, provides refugees with an aid throughout their experiences of chronic disruption, offering them glimpses of future prospects and the ability to exercise a degree of agency; it allows them to have some feeling of control during this stage of existential impasse. All of our informants with newly gained residency used their smartphones to help navigate their new surroundings; as Kim and Lingel (2016: 232) argue, 'for transnational newcomers who lack alternate means of acquainting themselves with their surroundings, smartphones offer particularly advantageous means of orienting themselves, finding directions, and discovering new places'. Nasir proudly showed off his numerous Danish apps on his smartphone including banking, travel and various apps for supermarket offers but indicated that Google translate and Danish language apps were the most important. Both Nasir and Mubarak claimed their smartphones are the most important objects in their lives, as highlighted by Mubarak stating:

If you took the internet from us it is like a fish out of water. No-one can [manage]. If you want to harm someone then you just take their phone away.

Gillespie et al. (2016: 11) similarly reported refugees claiming that their smartphone is 'more important than food or shelter'. For Mubarak, the significance of having a smartphone had been heightened due to his experience of losing his during the latter part of his journey. The first thing he did after obtaining residency was to buy a brand new iPhone, which symbolised the start of his transition into a new life. In addition to playing a key role in the process of integrating into Denmark, the smartphone also allowed Mubarak to stay in contact with his Syrian friends, many of whom had taken similar journeys to different European countries. His smartphone allows him to receive social recognition amongst his peers, thus fulfilling an important existential need (Hage 2005). Mubarak was also aware of the potential downside of having a new smartphone due to Danes' perceptions of refugees, in part promoted by negative reports in the media (Gillespie et al. 2016; Leurs 2017; Dekker et al. 2018; Dempsey and McDowell 2018). As he explained:

I know that many of the Danish people look at the refugees with their fancy iPhone 6 and think I [Danes] have only iPhone 4 with a broken screen but they don't know the story and how much we need it.

In contrast to Nasir and Mubarak, Abdul was living with his wife and newly born baby girl. He was focusing on trying to achieve his aspirations of becoming an architectural engineer and being able to provide for his new family. He used his smartphone to try to keep track of the different organisations he was in contact with, including the jobcentre, potential 
universities and the school where he was studying maths. Abdul explained how the need to constantly be online had become stressful:

You know I think everything is becoming more and more complex and if you don't have access to this system you will be a little bit excluded and you can't be integrated in the Danish society... Even if the battery is run out then you feel stressed. Everything is turned to digital. ... So it is stressful I think because just try to feel that you don't have this device [smartphone] and you feel yourself more free.

Abdul clearly struggled with how much time he had to spend on his smartphone but despite this, he emphasized that smartphones were not a luxury but a necessity to be able to settle and build a new life in Denmark; they serve as an important existential lifeline as without one you cease to be visible in Danish society, where so much communication takes place online. Moreover, the social pressure he felt to be online all the time and constantly communicate with family members elsewhere resulted in an overwhelming feeling of being trapped. The sense of obligation to others (Wilding 2006; Kaufmann 2018a) infiltrated how he felt about maintaining transnational social relations. As he explained:

There is no time in order for me to rest to see what I have to do ... so I don't think it is a good idea to spend all my time over the phone to communicate ... I don't know but I think I feel more free without a smartphone because I can spend my whole time to myself ... but as I said there is also positive because ... it makes the distance closer between my family and between friends.

The external pressure to communicate and be contactable that Abdul is experiencing is similar to Horst's (2006) argument that, despite the rise of ICTs being a blessing in many ways, it can also be a burden due to the increased expectation of maintaining transnational social relations. As Kaufman (2018) claims, Syrian refugees in Austria also felt a moral responsibility to stay in close contact with family members left behind.

Despite Masood having a relatively stable economic situation, since he had gained employment with Maersk 18 months after arriving in Denmark, he and his wife are struggling to adapt to their new surroundings. They talked repeatedly about the difficulties of integrating in Denmark, as well as how Syrian refugees are viewed in the eyes of many Danes:

Sada: It is because Denmark didn't want refugees and didn't want to help. They want to make our life very difficult.

Masood: The atmosphere is so negative. When we walk on the street, when we try to talk to someone we don't feel comfortable or welcome. They always look afraid of us maybe they don't want us but you know we are sensitive as a family.

Pace (2018: 783) similarly reports the challenges Syrians face in Denmark since negative stereotypes of refugees are common and Denmark has a one-way approach to assimilation, whereby 'immigrants are expected to assimilate Danish culture and leave their origins behind.' As Leurs (2017: 680) claims, refugees in Europe are "typically 'othered, mistrusted and feared". Smartphones are an essential tool for our informants as they struggle to establish new lives, especially for aiding their physical mobility around the city and trying to understand the many communications they receive from the Danish state. With a rather ironic tone in his voice, Masood recounted how: 
We are new and don't know anything so they send to us letter in Danish. Not even normal Danish but official Danish and you have to understand all of this. So you have to Google translate all the time.

The practical and existential navigation of our informants are thus interrelated; their smartphone both helps them physically orientate themselves and plays a role in assisting them in trying to come to terms with their new lives and futures in Denmark. Although accessing tools such as Google translate on their smartphones can help with understanding important documentation, it is of limited use in relation to aiding refugees integrate into their new society; not being able to communicate easily with Danes is an indication of our informants' feelings of being on the periphery of Danish society.

Masood and Sada were also using their smartphones to maintain transnational social relations with their extended families, who were either still living in Syria or had relocated elsewhere. As Wilding (2006) also found in her study of transnational families scattered across continents, ICTs do not replace family practices but rather support existing family relations and contribute to breaking down some of the effects of the physical distance. For Sada, keeping in contact with her mother was especially important:

Everyday my mum is sending a text 'Good morning. How are you?' So we just check in on each other. Everyday. Everyday! Because her area is very dangerous she stays in her home.

Back in Syria, Sada used to visit or speak with her mother everyday so maintaining constant contact with her brings a sense of normality and confirms that her mother is still alive. Whilst Sada is struggling to build up a new life in Denmark, she is acutely aware that the majority of her social network is still in danger, physically living through the war in Syria.

\section{Conclusion}

This paper has illustrated the multiple ways in which smartphones are a vital tool at all stages of Syrian refugees' journeys to Europe including: aiding navigation, accessing the 'online community', contacting 'smugglers', taking and sharing photographs, translating, maintaining contact with family and friends, and building transnational social relations. Our respondents used their smartphones to inform their migration decisions, both prior to and during their journeys, gleaning information primarily via the refugee 'online community' (cf. Zijlstra and Van Liempt, 2017; Dekker et al. 2018). Accessing WiFi zones was shown not only to be essential in order to access this information, but also offered refugees an existentially safe zone as connecting online created a sense of familiarity at times of extreme uncertainty. Even when offline, smartphone technology enabled them to trace their route and importantly ground themselves existentially in the sense of being physically present as a dot on a smartphone. The smartphone was thus an aid in the attunement process to the new fields our informants had to navigate (Vigh 2009a). Expectations of what their lives would become grew as they progressed towards their destination; they were constantly in tune with their surroundings as they tried to socially navigate the environments they found themselves in. As Borkert et al. (2018: 9) also found for Syrian and Iraqi refugees in Germany, refugees are not passive victims fleeing misery but 'actively escape using a wide range of resources and skills available to them'.

Smartphones continue to play a central role for newly arrived Syrian refugees in Denmark as they try to establish their lives in uncertain new surroundings. Especially during the asylum phase, when they feel physically isolated from Danish society living in small rooms with 
nothing to do, being able to connect to WiFi via their smartphones enables them to kill time and bring more familiar faces and settings into their rooms. Even after being granted residency, the settlement process is interrupted by disrupted expectations as once again they find their imagined futures and aspirations are not being fulfilled. Their smartphones continue to be an essential tool as they try to build new lives in Denmark, and for maintaining their transnational social relations with family and friends who are spread around the world (Gillespie et al. 2016; UNHCR 2016b; Kutscher and Kreb 2018).

Bringing in the voices and experiences of Syrian refugees, this paper has extended the emerging research focus on digital migration studies, illustrating how smartphones play an important existential as well as technological role within migration infrastructure, aiding refugees gain access to the migration industry and playing a key role in shaping their journeys. As we show, smartphones are literally existential orientating devices, which end up as life-lines in vital ways. Although the periods of disruption the refugees experience remain a constant, their smartphones play an important role in replacing the uncertainty and vacuum that emerges with intimacy and familiarity. Despite refugees' decision-making processes and journeys varying, the disruption to their imaginings and future possibilities affected them all.

The concept of 'chronic disruption' developed in the paper indicates the constant, though varied, hurdles that the refugees have been facing since the outbreak of the Syrian crisis in 2011. The futures they had imagined for themselves are not coming into fruition as they are constantly disrupted; they experience consecutive stop-starts reaching a place they feel relieved to have made it to but then getting stuck as their imaginings are disrupted once again. In essence, they experience disrupted becomings. While, as this paper has shown, the refugees' journeys are never ending, their smartphones play a key role in their attempts to navigate the chronic disruption they experience, aiding them physically and existentially.

\section{References}

Alencar, A. 2018 Refugee integration and social media: a local and experiential perspective, Information Communication and Society, 21:11, 1588-1603

Andersson, R. 2014. Illegality Inc. Clandestine migration and the business of bordering Europe. Oakland: University of California Press.

Becker, G. 1998. Disrupted Lives: How People Create Meaning in a Chaotic World, Berkeley, University of California Press.

Becker, G., Beyene, Y. \& Ken, P. 2000. Memory, Trauma, and Embodied Distress: The Management of Disruption in the Stories of Cambodians in Exile. Ethos, 28, 320-345.

Bendixen, D. 2018 What are the chances of being granted asylum? 28.11.2018 http://refugees.dk/en/facts/numbers-and-statistics/what-are-the-chances-of-being-grantedasylum/

Berti, B. 2015. The Syrian refugee crisis: regional and human security implications. Strategic Assessment, 17, 41-52.

Borkert, M., Fisher, K.E. and Yafi, E. 2018 The best, the worst and the hardest to find: How people, mobiles and social media connect migrants in(to) Europe, Social Media and Society, 1-11. 
Central Intelligence Agency 2014 The World Factbook.

https://www.cia.gov/library/publications/the-world-factbook/fields/2151.html

Coates, J. 2013. Everyday mobility: the normalization of China-Japan migratory flows and their "Everyday Practice". International Review of Social Research, 3, 7-26.

Collyer, M. 2007 In-between places: trans- Saharan transit migrants in Morocco and the fragmented journey to Europe, Antipode, 39(4): 668-690.

Cranston, S. 2016 Producing migrant encounter: Learning to be a British expatriate in Singapore through the Global Migration Industry, Environment and Planning D: Society and Space, 34(4): 655671.

Cranston, S., Schapendonk, J., Spaan, E. 2018 New directions in exploring the migration industries: introduction to special issue, Journal of Ethnic Migration Studies, 44(4): 543-557.

Dekker, R., Engbersen, G., Klaver, J. and Vonk, H. 2018 Smart refugees: How Syrian asylum migrants use social media information in migration decision-making, Social Media and Society, 1-11

Dempsey, K.E. and McDowell, S. 2018 Disaster depictions and geopolitical representations in Europe's migration 'Crisis', Geoforum https://doi.org/10.1016/j.geoforum.2018.11.008.

Desjarlais, R. and Throop, C. J. 2011. Phenomenological Approaches in Anthropology. Annual Review of Anthropology, Vol 40: 87-102

Ehrkamp, P. 2017 Geographies of migration I: Refugees, Progress in Human Geography, 41(6): 813-822.

Erlich, R. 2014. Inside Syria: the backstory of their civil war and what the world can expect, Amherst, Prometheus Books.

Frouws, B., Phillips, M., Hassan, A. and Twigt, M. 2016 Getting to Europe the 'WhatsApp' way, RMMS Horn of Africa and Yemen, Danish Refugee Council http://www.regionalmms.org/indexBriefingPaper.html

Gillespie, M., Ampofo, L., Cheesman, M., Faith, B., Iliadou, E., Issa, A., Osserian, S. and Skleparis, D. 2016 Mapping refugee media journeys: Smartphones and social media networks, Research Report, The Open University/France Medias Monde

Gillespie, M., Osserian, S. and Cheesman, M. 2018 Syrian refugees and the digital passage to Europe: Smartphone infrastructures and affordances, Social Media and Society, 1-12

Griffiths, M. 2013. Living with uncertainty: indefinite immigration detention. Journal of Legal Anthropology, 1, 263-286.

Haddon, L. 2004. Information and Communication Technologies in Everyday Life, Oxford, Berg.

Hage, G. 2005. A not so multi-sited ethnography of a not so imagined community. Anthropological Theory 5, 463-475. 
Harney, N. 2013. Precarity, affect and problem solving with mobile phones by asylum seekers, refugees and migrants in Naples, Italy, Journal of Refugee Studies, 26(4): 541-557.

Horst, H. A. 2006. The blessings and burdens of communication: cell phones in Jamaican transnational social fields. Global Networks-a Journal of Transnational Affairs, 6, 143-159.

Horst, H. A. \& Taylor, E. B. 2014. The role of mobile phones in the mediation of border crossings: A study of Haiti and the Dominican Republic. Australian Journal of Anthropology, 25, 155-170.

Huizinga, R.P. and van Horen, B. 2018. Everyday geographies of belonging: Syrian refugee experiences in the Northern Netherlands, Geoforum 96: 309-317

International Labour Organization 2016 Syrian Refugees and Labour Market: ILO welcomes the introduction of work permits for refugees in Turkey.

http://www.ilo.org/ankara/news/WCMS_444117/lang--en/index.htm

ITU 2016 ICT Facts and Figures 2016

http://www.itu.int/en/ITUD/Statistics/Pages/facts/default.aspx

Johnson-Hanks, J. 2002. On the limits of life stages in ethnography: Toward a theory of vital conjunctures. American Anthropologist, 104, 865-880.

Karim, K. H. 2003. Mapping diasporic mediscapes. In: Karim, K. H. (ed.) The Media of Diaspora. London: Routledge.

Kaufmann, K. 2018a Navigating a new life: Syrian refugees and their smartphones in Vienna, Information, Communication and Society, 21(6): 882-898

Kaufmann, K. 2018b The smartphone as a snapshot of its use: Mobile media elicitation in qualitative interviews, Mobile Media and Communication, 6(2): 233-246

Kim, H. and Lingel, J. 2016 Working through paradoxes: transnational migrants' urban learning tactics using locative technology, Mobile Media and Communication, 4(2): 221-236

Kutscher, N. and Kreb, L.M. 2018 The ambivalent potentials of social media use by unaccompanied minor refugees, Social Media and Society, 1-10

Langevang, T. 2008. 'We are managing!' Uncertain paths to respectable adulthoods in Accra, Ghana. Geoforum, 39, 2039-2047.

Latonero, M. and Kift, P. 2018 On digital passages and borders: refugees and the new infrastructure for movement and control, Social Media and Society, 1-11.

Leurs, K. 2017 Communication rights from the margins: politicizing young refugees' smartphone pocket archives, the International Communication Gazette, 79(6-7): 674-698.

Leurs, K. and Smets, K. 2018 Five questions for digital migration studies: learning from digital connectivity and forced migration in(to) Europe, Social Media and Society, 1-16 
Lim, S.S., Bork-Huffer and Yeoh, B.S.A. 2016 Mobility, migration and new media: manoeuvring through physical, digital and liminal spaces, New Media and Society, 18(10): 2147-2154

Loh, T. 2016. Digitzing Refugees: The effect of technology on forced displacement. Journal of Communication, Culture and Technology, 1-20.

Lucht, H. 2012. Darkness Before Daybreak: African migrants living on the margins in southern Italy today, Berkeley, University of California Press.

Maitland, C., Tomaszewski, B., Belding, E. \& Fisher, K. 2015. Your mobile phone use Penn State: Penn State College of Information Sciences.

Miller, D., Costa, E., Haynes, N., Mcdonald, T., Nicolescu, R., Sinanan, J., Spyer, J., Venkatraman, S. \& Wang, X. 2016. How the World Changed Social Media, London, UCL Press.

Mitchell, J. C. 1983. Case and situation analysis. The Sociological Review, 31, 187-211.

O'Reilly, K. 2009. Key Concepts in Ethnography, London, Sage.

Pace, M. 2018 Overcoming bordering practices through the arts: The case of young Syrian refugees and their Danish counterparts in Denmark, Geopolitics, 23(4): 781-802.

Panagakos, A. N. \& Horst, H. A. 2006. Return to Cyberia: technology and the social worlds of transnational migrants. Global Networks-a Journal of Transnational Affairs, 6, 109-124.

Robertson, A. 2017 Infrastructures of insecurity: Housing and language testing in Asia-Australia migration, Geoforum, 82: 13-20.

Seeberg, P. 2015. The EU and the Syrian Crisis: The Use of Sanctions and the Regime's Strategy for Survival. Mediterranean Politics, 20, 18-35.

Schapendonk, J. 2017 Navigating the migration industry: migrants moving through an African-European web of facilitation/control, Journal of Ethnic and Migration Studies https://doi.org/10.1080/1369183X.2017.1315522

Schapendonk, J., van Liempt, I., Schwarz, I. and Steel, G. 2018 Re-routing migration geographies: migrants, trajectories and mobility regimes, Geoforum (in press)

Schaub, M. L. 2012. Lines across the desert: mobile phone use and mobility in the context of transSaharan migration. Information Technology for Development, 18, 126-144.

UNHCR 2010 Convention and Protocol Relating to the Status of Refugees, Geneva: United Nations Refugee Agency. http://www.unhcr.org/3b66c2aa10.html

Vigh, H. E. 2006. Social death and violent life chances. In: Christiansen, C., Utas, M. \& Vigh, H. E. (eds) Navigating youth generating adulthood: social becoming in an African context. Uppsala: Nordisk Afrikainstitut.

Vigh, H. 2008. Crisis and chronicity: Anthropological perspectives on continuous conflict and decline. Ethnos, 73, 5-24. 
Vigh, H. 2009a. Motion squared: A second look at the concept of social navigation. Anthropological Theory, 9, 419-438.

Vigh, H. 2009b. Wayward Migration: On Imagined Futures and Technological Voids. Ethnos, 74, 91-109.

Vradis, A., Papada, E., Painter, J. and Papoutsi, A. 2019 New borders: Hotspots and the European migration regime, Pluto Press, London

Wall, M., Campbell, M. O. \& Janbek, D. 2017. Syrian refugees and information precarity. New Media \& Society, 19(2): 240-254

Whyte, Z. 2011. Enter the myopticon. Anthropology Today, 27, 18.

Wilding, R. 2006. 'Virtual' intimacies? Families communicating across transnational contexts. Global Networks-a Journal of Transnational Affairs, 6, 125-142.

Witteborn, S. 2015. Becoming (Im)Perceptible: Forced Migrants and Virtual Practice. Journal of Refugee Studies, 28, 350-367.

Yazgan, P., Utku, D. E. \& Sirkeci, I. 2015. Editorial: Syrian Crisis and Migration. Migration Letters, 12, 181-192.

UNHCR 2016a Global Appeal 2016-2017, Middle East and North Africa Chapter, http://www.unhcr.org/564da0e49.html

UNHCR 2016b Connecting refugees: How internet and mobile connectivity can improve refugee well-being and transform humanitarian action, UNHCR, Geneva

UNHCR 2018. Syria Regional Refugee Response

http://data.unhcr.org/syrianrefugees/regional.php

Zijlstra, J. and van Liempt, I. 2017 Smart(phone) travelling: understanding the use and impact of mobile technology on irregular migration journeys, International Journal of Migration and Border Studies 3(2/3): 174-191 